\title{
Markers Involved in Innate Immunity and Neutrophil Activation are Elevated during Acute Human Anaphylaxis: Validation of a Microarray Study
}

\author{
Abbie Francis $^{a, b}$ Erika Bosio ${ }^{a, b}$ Shelley F. Stone ${ }^{a, b}$ \\ Daniel M. Fatovich ${ }^{\mathrm{a}-\mathrm{c}}$ Glenn Arendts ${ }^{\mathrm{a}-\mathrm{d}}$ Stephen P.J. MacDonald ${ }^{\mathrm{a}-\mathrm{c}, \mathrm{e}}$ \\ Sally Burrows ${ }^{f}$ Simon G.A. Brown ${ }^{a-c, g}$ \\ ${ }^{a}$ Centre for Clinical Research in Emergency Medicine, Harry Perkins Institute of Medical Research, Perth, WA, \\ Australia; ${ }^{b}$ Division of Emergency Medicine, Medical School, University of Western Australia, Perth, WA, Australia;

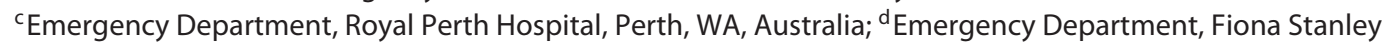 \\ Hospital, Murdoch, WA, Australia; ${ }^{e}$ Emergency Department, Armadale-Kelmscott Memorial Hospital, Mount \\ Nasura, WA, Australia; ${ }^{f}$ School of Medicine and Pharmacology, University of Western Australia, Perth, WA, Australia; \\ ${ }^{g}$ Emergency Department, Royal Hobart Hospital, Hobart, TAS, Australia
}

\section{Keywords}

Allergy · Anaphylaxis · Myeloid cells $\cdot$ Neutrophils

\begin{abstract}
Background: We have previously identified the upregulation of the innate immune response, neutrophil activation, and apoptosis during anaphylaxis using a microarray approach. This study aimed to validate the differential gene expression and investigate protein concentrations of "hub genes" and upstream regulators during anaphylaxis. Methods: Samples were collected from patients with anaphylaxis on their arrival at the emergency department, and after 1 and $3 \mathrm{~h}$. mRNA levels of 11 genes (interleukin-6 [IL-6], IL-10, oncostatin M [OSM], S100A8, S100A9, matrix metalloproteinase 9 [MMP9], FASL, toll-like receptor 4 [TLR4], MYD88, triggering receptor expressed on myeloid cells 1 [TREM1], and cluster
\end{abstract}

\section{KARGER}

E-Mail karger@karger.com www.karger.com/jin (C) 2018 The Author(s) Karger
Published by S. Karger AG, Basel
Open access This article is licensed under the Creative Commons AttributionNonCommercial-NoDerivatives 4.0 International License (CC BY NC-ND) (http://www.karger.com/Services/OpenAccessLicense). Usage and distribution for commercial purposes as well as any distribution of modified material requires written permission. of differentiation 64 [CD64]) were measured in peripheral blood leucocytes using qPCR. Serum protein concentrations were measured by ELISA or cytometric bead array for 6 of these candidates. Results: Of 69 anaphylaxis patients enrolled, 36 (52\%) had severe reactions, and 38 (55\%) were female. Increases in both mRNA and protein of IL-10, S100A9, MMP9, and TREM1 were observed. OSM, S100A8, $T L R 4$, and CD64 were upregulated and IL-6 protein concentrations were increased during anaphylaxis. Both FASL and soluble Fas ligand decreased during anaphylaxis. Conclusion: These results provide evidence for the involvement of innate immune pathways and myeloid cells during human anaphylaxis, validating previous microarray findings. Elevated S100A8, S100A9, TLR4, and TREM1 expression, and increased S100A9 and soluble TREM1 protein concentrations strongly suggest that neutrophils are activated during acute anaphylaxis.

(c) 2018 The Author(s)

Published by S. Karger AG, Basel

Dr. Abbie Francis

Centre for Clinical Research in Emergency Medicine

Harry Perkins Institute of Medical Research

Level 6 MRF Building, Rear 50 Murray Street, Perth, WA 6000 (Australia)

E-Mail Abbie.Francis@uwa.edu.au 


\section{Introduction}

Allergies are a global health concern, with increases in the numbers of adverse reactions to foods in children and drugs in adults [1]. The rapid progression from the onset of allergic symptoms through to a potentially life-threatening reaction affecting multiple organ systems is a hallmark of anaphylaxis [2]. The immune mechanisms driving human anaphylaxis are poorly understood. However, an IgE-mediated pathway, involving the activation of mast cells, has been the predominant focus of clinical investigation [3]. During this process, the initial exposure to an allergen stimulates the production of allergen-specific IgE, which bind to IgE receptors on the surface of mast cells or basophils. On a subsequent exposure, allergens bind to these antibodies, causing IgE receptor crosslinking, which initiates degranulation [4]. This releases an array of mediators including histamine and mast cell tryptase that contribute to the physiological signs of anaphylaxis such as vasodilation and bronchoconstriction [5, 6]. Much still remains unknown about how the localized mast cell signal becomes rapidly amplified into potentially lethal systemic immune activation.

A previous microarray study performed in our laboratory aimed to investigate differential gene expression during the course of anaphylaxis [7]. This study investigated 6 patients with moderate anaphylaxis who were sampled over the first 3 hours after arrival at the emergency department. An increasing number of genes were differentially expressed over this time, culminating in a storm of genetic activation. Several key pathways including inflammation, innate immunity, apoptosis, neutrophil activation, and chemotaxis were upregulated, suggesting these pathways play central roles in the anaphylactic response [7]. The present study aimed to investigate some of these processes more closely during anaphylaxis by analyzing the mRNA expression of some important genes in peripheral blood leucocytes and their corresponding protein levels in serum/plasma, where possible.

The selected targets were identified in our previous microarray study [7] as either "hub genes" or upstream regulators for the pathways of interest including: interleukin (IL)-6; IL-10; oncostatin M (OSM); S100 calciumbinding proteins A8 (S100A8) and A9 (S100A9); matrix metalloproteinase 9 (MMP9); Fas ligand (FasL); toll-like receptor 4 (TLR4); myeloid differentiation primary response 88 (MyD88); triggering receptor expressed on myeloid cells 1 (TREM1); and cluster of differentiation 64 (CD64). IL-6, IL-10, and OSM are cytokines that play important roles in innate immunity by performing either pro- or anti-inflammatory functions $[8,9]$. S100A8 and S100A9 are proteins contained within phagocytes that are released following cellular activation or damage [10]. They are known as danger-associated molecular patterns and the binding of extracellular S100A8/S100A9 to certain activating surface receptors including TREM1 and TLR4 (which associates with the intracellular adaptor protein MyD88) amplifies inflammation [11]. MMP9 is released from myeloid cells, primarily neutrophils, following their activation/degranulation [12]. FasL is a surface protein that binds to Fas receptor and stimulates apoptosis of susceptible Fas-expressing cells [13]. However, once cleaved by matrix metalloproteinases, soluble FasL competes with surface FasL for Fas binding and does not trigger apoptosis. Therefore, while surface FasL is proinflammatory, high concentrations of soluble FasL promote cell survival [14]. Finally, CD64 is the high-affinity $\operatorname{IgG}$ receptor present on the surface of macrophages, monocytes, and neutrophils. Anaphylaxis via an IgG-mediated pathway has been demonstrated in experimental mouse models but is not well studied in humans [15].

Investigation into the changes in mRNA expression and protein concentrations of this panel of targets would provide insight into the cell types and pathways activated during anaphylaxis and validate the results of our previous work.

\section{Materials and Methods}

\section{Patient Recruitment}

Study participants and healthy controls were enrolled in our prospective, observational Critical Illness and Shock Study (CISS) between September 2010 and January 2014 in 4 Australian Emergency Departments. The methodology for CISS has been previously described [16]. Patients enrolled in the study meet a case definition of critical illness, which excludes mild (skin-only) allergic reactions, and then undergo serial blood sampling and clinical data collection at protocolled time points. The time points for this study were as soon as practicable after enrolment criteria were identified (T0), and $1 \mathrm{~h}$ (T1) and $3 \mathrm{~h}$ after enrolment (T3). These time points reflect those from the microarray study. At each time point, $1 \times 3.5 \mathrm{~mL}$ serum separating tube and $2 \times 2.5 \mathrm{~mL}$ Blood RNA PAXgene ${ }^{\mathrm{TM}}$ tubes (PreAnalytiX GmbH, Switzerland) were collected. Serum was collected, aliquoted, and stored immediately at $-80^{\circ} \mathrm{C}$ until analysis. RNA PAXgene ${ }^{\mathrm{TM}}$ tubes were collected and placed immediately at $4{ }^{\circ} \mathrm{C}$, then transferred to $-20^{\circ} \mathrm{C}$ within $72 \mathrm{~h}$, before final storage at $-80^{\circ} \mathrm{C}$ until analysis.

\section{Ethics Approval and Consent}

Ethics approval was obtained from the Human Research Ethics Committees at each hospital (Royal Perth Hospital, Fremantle Hospital, Armadale-Kelmscott Memorial Hospital: EC 2009/080; Austin Hospital: H2012/04477). Since the need for emergency care 
took priority, waiver of initial consent was approved under the provision of paragraph 2.3.6 of the National Health and Medical Research Council Ethical Conduct guidelines (2007). Once the study could be explained to them, fully informed written consent was obtained. Patients were given the option of declining further involvement and allowing the destruction of samples collected up to that point.

\section{Patient Cohort}

We selected cases that satisfied a clinical definition of anaphylaxis based on National Institute of Allergy and Infectious Diseases/Food Allergy and Anaphylaxis Network (NIAID/FAAN) criteria [2]. To test for differences associated with severity, cases were reviewed by 3 physician investigators (S.G.A.B., D.M.F., and G.A.) and classified into 2 severity groups, moderate or severe anaphylaxis, based on clinical features according to established criteria [17]. Both moderate and severe anaphylaxis involves multiple organ systems, while the presence of hypoxemia $\left(\mathrm{SpO}_{2} \leq 92 \%\right.$ or cyanosis), hypotension (systolic blood pressure $<90 \mathrm{~mm} \mathrm{Hg}$ ), and/or neurological compromise (confusion, collapse, loss of consciousness, or incontinence) classifies a reaction as severe. This classification was undertaken separately and blinded to the laboratory analyses. Many of the patients included in this study were also sampled for a separate study investigating neutrophil activation during anaphylaxis [18].

\section{RNA Extraction}

RNA was extracted using PAXgene ${ }^{\mathrm{TM}}$ Blood RNA Extraction Kits (PreAnalytiX GmbH, Switzerland) by automation with a QIAcube instrument (Qiagen, USA). The purity and integrity of the RNA samples were assessed using a NanoDrop spectrophotometer (Thermo Fisher Scientific, USA) and a 2100 Bioanalyzer (Agilent, USA). Samples with RNA integrity number (RIN) values $<7$ and total RNA $<1 \mu \mathrm{g}$ were excluded. As a result, the quality of included samples was very high (median [interquartile range] 260/280 absorbance ratio: 2.04 (0.09); and median (interquartile range) RIN: $8.7(0.9)$

\section{Quantitative PCR}

Complementary DNA (cDNA) was synthesized using SuperScript ${ }^{\mathrm{TM}}$ III reverse transcriptase according to the manufacturer's protocol (Thermo Fisher Scientific, USA) and stored immediately at $-20^{\circ} \mathrm{C}$. Quantitative PCRs (qPCRs) were performed in a total volume of $10 \mu \mathrm{L}$, comprising $37.5 \mathrm{ng}$ of each primer (online suppl. Table S1; for all online suppl. material, see www.karger. com/doi/10.1159/000492301), $0.5 \mu \mathrm{L}$ of LightCycler ${ }^{\circledR} 480$ ResoLight Dye (Roche Diagnostics, USA), and $1 \mu \mathrm{L}$ of $10 \times$ PCR buffer, $5 \mathrm{mM} \mathrm{MgCl}_{2}, 0.2 \mathrm{mM}$ dNTPs, 0.33 Units Platinum ${ }^{\circledR}$ Taq DNA Polymerase (all from Thermo Fisher Scientific, USA), and $2 \mu \mathrm{L}$ of 1/10 cDNA. A Rotor-Gene ${ }^{\mathrm{TM}} 6000$ (Corbett, Australia) was used to optimize annealing temperatures and magnesium concentrations for each set of primers. Triplicate reactions were set up in 384 well plates and a ViiA ${ }^{\mathrm{TM}} 7$ Real-Time PCR System (Applied Biosystems, USA) was used with the following cycling conditions: $50^{\circ} \mathrm{C}$ for $2 \mathrm{~min} ; 95^{\circ} \mathrm{C}$ for $10 \mathrm{~min}$; and followed by 40 cycles of $95^{\circ} \mathrm{C}$ for $15 \mathrm{~s}$, annealing temperature (online suppl. Table S1) for $15 \mathrm{sec}$, and $72^{\circ} \mathrm{C}$ for $15 \mathrm{~s}$. Single product amplification was confirmed using dissociation curves established by increasing the temperature of the samples from 60 to $95^{\circ} \mathrm{C}$ stepwise at $0.05^{\circ} \mathrm{C}$ per second.

Innate Immunity and Neutrophils in Anaphylaxis

\section{Template Cloning for Standard Curve Preparation}

RNA extracted from PBLs stimulated overnight with phorbol myristate acetate (Sigma-Aldrich, Australia) was used to prepare cDNA. Targets of interest were amplified using the same primers used for qPCR and products were ligated into $\mathrm{pGEM}^{\circledR}$-T Easy vectors (Promega, Australia). JM109 competent cells (Promega, Australia) were transformed with the construct. Ampicillin-resistant colonies were grown in liquid culture and plasmid DNA was prepared using the QIAprep Spin Miniprep Kit (Qiagen, Australia). Cloned sequences were verified on both strands using Sanger sequencing by the Australian Genome Research Facility. Plasmids were linearized with AatII (New England Biolabs, USA) and standard curves were prepared.

\section{Analysis using qBase Plus}

Viia7 $^{\mathrm{TM}}$ software (Thermo Fisher Scientific, USA) determined Cq values using the Baseline Threshold algorithm. Three reference genes, RPS18, HPRT, and YWHAZ were determined as appropriate to normalize Cq data using qBase+ software, version 2.6 (Biogazelle, Belgium). Replicates that varied by greater than $0.8 \mathrm{Cq}$ were excluded.

\section{Measuring Protein Concentrations}

Serum concentrations of IL-6, IL-10, and soluble FasL were measured by cytometric bead array flex sets (BD Biosciences, USA) as described previously [5]. Samples were diluted 1:4 in assay diluent, measured in duplicate using a FACSCanto ${ }^{\mathrm{TM}}$ II flow cytometer (BD Biosciences, USA), and analyzed using FCAP Array $^{\mathrm{TM}}$ version 3.0 software (Soft Flow, Hungary). The lower limits of detection were 1.13 pg/mL IL-6; 0.092 pg/mL IL-10; and $1.838 \mathrm{pg} / \mathrm{mL}$ FasL, as defined by the manufacturer. Serum concentrations of MMP9, TREM1, and S100A9 were measured using ELISA (DuoSet ${ }^{\circledR}$ R\&D Systems, USA) according to the manufacturer's instructions. The lower limits of detection were $22.06 \mathrm{pg} / \mathrm{mL}$ MMP9; $33.15 \mathrm{pg} / \mathrm{mL}$ TREM1; and $22.06 \mathrm{pg} / \mathrm{mL}$ S100A9. Intra- and inter-assay CVs for the ELISAs were 1.8 and 9.3\% for MMP9, 4.9 and $13.0 \%$ for TREM1, and 2.9 and $18.5 \%$ for S100A9. The protein concentrations of the remaining targets were not measured due to limited sample availability, lack of expression in serum, or duplication in the case of S100A8/ S100A9.

\section{Statistical Analysis}

Due to small sample sizes, differences in mRNA expression between groups were assessed using nonparametric tests. Where protein targets had concentrations below the assay's detection limits, differences in the proportion of detectable samples in each group were assessed using Fisher's exact tests. The HolmBonferroni step-down method was used to adjust the critical value to account for multiple comparisons. When groups had $>50 \%$ samples detectable, results were log-transformed to normalize the distribution of data. Tobit regression models were used to assess differences in protein concentrations without excluding the censored data. In targets where all samples had detectable protein concentrations, linear regression models were used to investigate differences between groups. Both Tobit and linear regression models were bootstrapped to produce $p$ values that were robust to departures from model assumptions. All statistical analyses were performed using Stata version 12.1 (StataCorp, USA). 
Table 1. Patient demographics and clinical observations

\begin{tabular}{|c|c|c|c|}
\hline & Moderate anaphylaxis & Severe anaphylaxis & All \\
\hline Number & 33 & 36 & 69 \\
\hline Age, years, mean $\pm S D$ & $36 \pm 15.4$ & $44 \pm 15.6$ & $40 \pm 15.9$ \\
\hline Gender, male, $n(\%)$ & $15(45)$ & $16(44)$ & $31(45)$ \\
\hline \multicolumn{4}{|l|}{ Cause, $n(\%)$} \\
\hline Drug & $7(21)$ & $19(53)$ & $26(38)$ \\
\hline Food & $18(55)$ & $5(14)$ & $23(33)$ \\
\hline Insect & $3(9)$ & $3(8)$ & $6(9)$ \\
\hline Physical (including food + exercise) & $2(6)$ & $3(8)$ & $5(7)$ \\
\hline Other/unknown & $3(9)$ & $6(17)$ & $9(13)$ \\
\hline Onset to enrolment, mins, median (IQR) & $75(47)$ & $72(64)$ & $75(50)$ \\
\hline \multicolumn{4}{|l|}{ Symptoms, $n(\%)$} \\
\hline Any skin feature & $32(97)$ & $36(100)$ & $68(99)$ \\
\hline Any GI feature & $11(33)$ & $18(50)$ & $29(42)$ \\
\hline Any respiratory feature & $32(97)$ & $29(81)$ & $61(88)$ \\
\hline Hypoxemia & - & $5(14)$ & $5(7)$ \\
\hline Cyanosis & - & $10(28)$ & $10(14)$ \\
\hline Any cardiovascular feature & $7(21)$ & $35(97)$ & $42(61)$ \\
\hline Hypotension & - & $26(72)$ & $26(38)$ \\
\hline LOC/Collapse & - & $12(33)$ & $12(17)$ \\
\hline \multicolumn{4}{|l|}{ Treatments, $n(\%)$} \\
\hline Adrenaline & $29(88)$ & $36(100)$ & $65(94)$ \\
\hline Pre-hospital & $8(24)$ & $18(50)$ & $26(38)$ \\
\hline Steroids & $19(58)$ & $27(75)$ & $46(67)$ \\
\hline Fluids & $16(48)$ & $27(75)$ & $43(62)$ \\
\hline Positive histamine* $\left.{ }^{*}>1.2 \mathrm{ng} / \mathrm{mL}\right)$ & $13(52)$ & $21(60)$ & $34(57)$ \\
\hline Positive $\mathrm{MCT}^{* *}(>11.4 \mathrm{ng} / \mathrm{mL}$, or $\Delta \mathrm{MCT}>2 \mathrm{ng} / \mathrm{mL})$ & $16(52)$ & $32(89)$ & $48(72)$ \\
\hline
\end{tabular}

$\wedge$ Adrenaline administered at any stage.

Note, due to sample availability:

* Histamine was measured by ELISA in 25 moderate and 35 severe patients at enrolment.

** MCT was measured by ImmunoCAP ${ }^{\circ}$ in 31 moderate and 36 severe patients at enrolment.

GI, gastrointestinal; IQR, interquartile range; LOC, loss of consciousness; MCT, mast cell tryptase; $\triangle \mathrm{MCT}$, difference between highest and lowest observed MCT concentrations. Skin features = erythema, urticaria, periorbital oedema, angioedema. GI features = nausea, vomiting, abdominal/pelvic pain, incontinence. Respiratory features = dyspnoea, stridor, wheeze, chest/throat tightness, hypoxemia, cyanosis. Cardiovascular features = dizziness, diaphoresis, confusion, hypotension, LOC, collapse.

\section{Results}

\section{Cohort Characteristics}

This study cohort consisted of 69 patients with a confirmed diagnosis of anaphylaxis, with 36 (52\%) of them having severe reactions. The patient demographics and clinical characteristics for each severity group are presented in Table 1. The majority of patients were female, accounting for 38 (55\%) reactions. The average age was 40 years, ranging from $16-85$ years. Both food and drug triggers each accounted for roughly one third of reactions, with most moderate reactions being food-induced and most severe reactions being drug-induced. The median time between the onset of symptoms and the first blood sample was $75 \mathrm{~min}$, ranging from 10 to $215 \mathrm{~min}$.

\section{Differences Evident at Enrolment (T0)}

The raw mRNA expression data is presented in Figure 1 , with the p-values presented in Table 2. At T0, the expressions of IL10 and OSM were different between the 3 groups (healthy controls, moderate, and severe anaphylaxis; $p \leq 0.002$ ). The expression of IL10 and OSM was lower in those with moderate anaphylaxis than that in healthy controls $(p<0.016)$. In contrast, the OSM expression was higher in those with severe anaphylaxis than that of healthy controls $(p=0.045)$, and higher in those with severe than moderate anaphylaxis $(p<0.001)$. IL-10 expression was also higher in those with severe than moderate anaphylaxis $(p<0.001)$, but no difference was found between those with severe anaphylaxis and healthy controls. After adjustment for multiple comparisons, there
66

J Innate Immun 2019;11:63-73 DOI: $10.1159 / 000492301$
Francis/Bosio/Stone/Fatovich/Arendts/ MacDonald/Burrows/Brown 


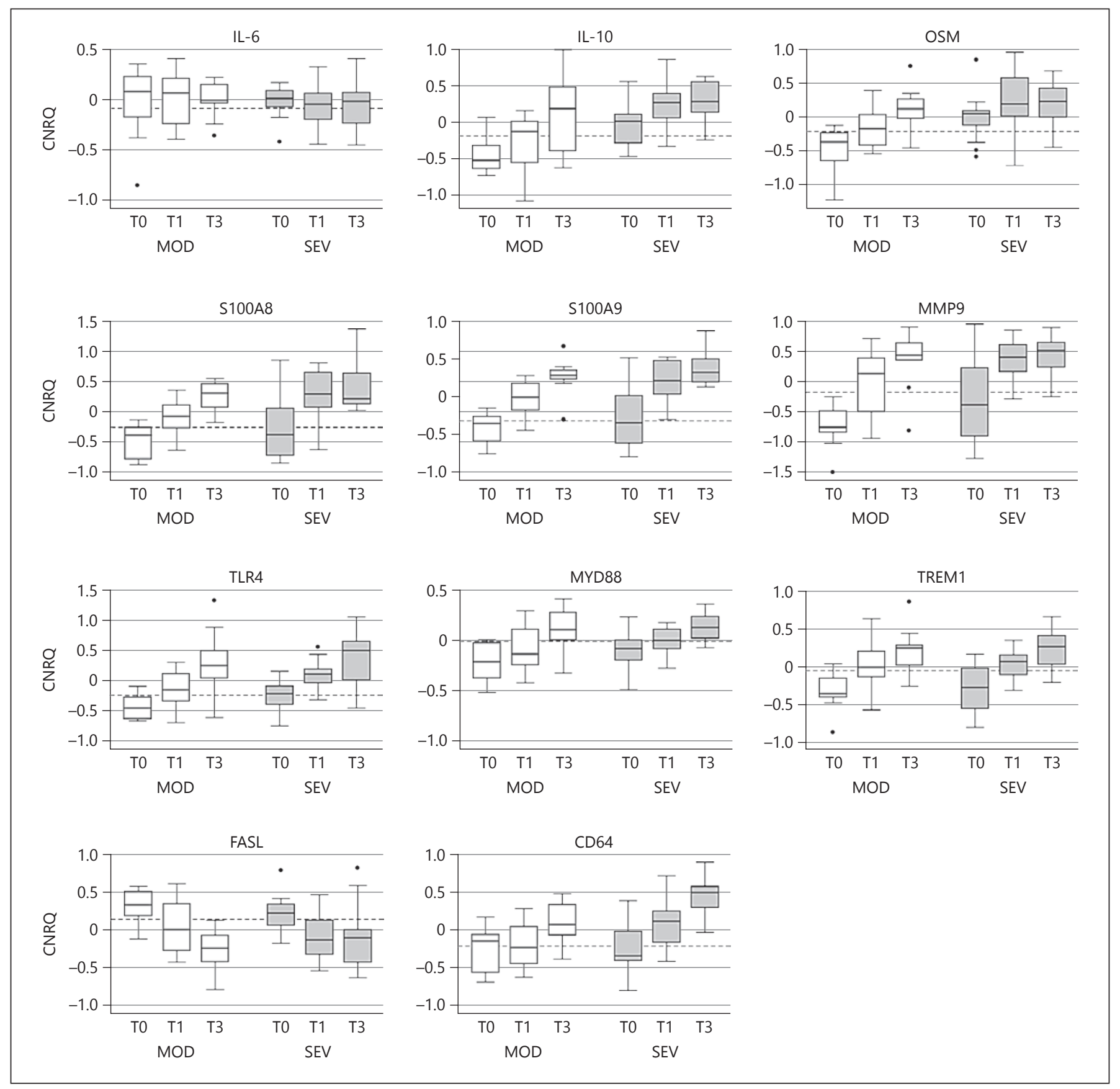

Fig. 1. Gene expression during anaphylaxis. Quantitative PCR was performed on mRNA extracted from peripheral blood leukocytes of moderate (MOD, $n=11$ ) and severe (SEV, $n=15$ ) anaphylaxis patients at the time of enrolment in the emergency department (ED) (T0), and again after one (T1) and 3 (T3) hours. Gene expression data are presented as calibrated normalized relative quantities
(CNRQ). Boxplots identify the median, upper and lower quartiles, and the range. Dotted lines indicate the median CNRQ of healthy controls $(n=20)$. Due to the number and complexity of comparisons, significant differences between groups are described in the results text and in Table 2 . 
Table 2. $p$ values for mRNA comparisons between reaction severities at each time point

\begin{tabular}{|c|c|c|c|c|c|c|c|c|c|c|c|c|}
\hline & $\begin{array}{l}\text { all } 3 \\
\text { groups }\end{array}$ & $\begin{array}{l}\text { HC vs. } \\
\text { MOD }\end{array}$ & $\begin{array}{l}\text { HC vs. } \\
\text { SEV }\end{array}$ & $\begin{array}{l}\text { MOD vs. } \\
\text { SEV }\end{array}$ & $\begin{array}{l}\text { all } 3 \\
\text { groups }\end{array}$ & $\begin{array}{l}\text { HC vs. } \\
\text { MOD }\end{array}$ & $\begin{array}{l}\text { HC vs. } \\
\text { SEV }\end{array}$ & $\begin{array}{l}\text { MOD vs. } \\
\text { SEV }\end{array}$ & $\begin{array}{l}\text { all } 3 \\
\text { groups }\end{array}$ & $\begin{array}{l}\text { HC vs. } \\
\text { MOD }\end{array}$ & $\begin{array}{l}\text { HC vs. } \\
\text { SEV }\end{array}$ & $\begin{array}{l}\text { MOD vs. } \\
\text { SEV }\end{array}$ \\
\hline IL-6 & 0.1974 & & & & 0.4526 & & & & 0.4649 & & & \\
\hline IL-10 & 0.0021 & 0.0029 & 0.1789 & 0.0003 & 0.0010 & 0.4835 & 0.0003 & 0.0012 & 0.0008 & 0.0568 & $<0.0001$ & 0.0478 \\
\hline OSM & 0.0022 & 0.0159 & 0.0448 & 0.0002 & 0.0147 & 0.4175 & 0.0028 & 0.0126 & 0.0010 & 0.0082 & 0.0002 & 0.2470 \\
\hline MMP9 & 0.0079 & 0.0009 & 0.1276 & 0.0248 & 0.0002 & 0.0662 & $<0.0001$ & 0.0187 & 0.0001 & 0.0004 & $<0.0001$ & 0.3205 \\
\hline FASL & 0.0418 & 0.0076 & 0.0616 & 0.1555 & 0.1014 & & & & 0.0005 & 0.0003 & 0.0013 & 0.2354 \\
\hline TLR4 & 0.0664 & & & & 0.0038 & 0.0906 & 0.0004 & 0.0540 & 0.0001 & 0.0014 & $<0.0001$ & 0.3362 \\
\hline $0.05 / 2$ & 0.0593 & & & & 0.6318 & & & & 0.0143 & 0.0187 & 0.0038 & 0.3828 \\
\hline TREM1 & 0.0251 & 0.0086 & 0.0167 & 0.3361 & 0.3538 & & & & 0.0012 & 0.0027 & 0.0005 & 0.4579 \\
\hline
\end{tabular}

Bolded $p$ values remained significant after application of Bonferroni-Holm step-down correction to adjust for multiple comparisons. Pairwise comparisons were performed when the Kruskal Wallis $p$ value for testing across all 3 groups was $<0.05$. HC, healthy control; MOD, moderete; SEV, severe.

Table 3. Proportion of samples with detectable protein concentrations

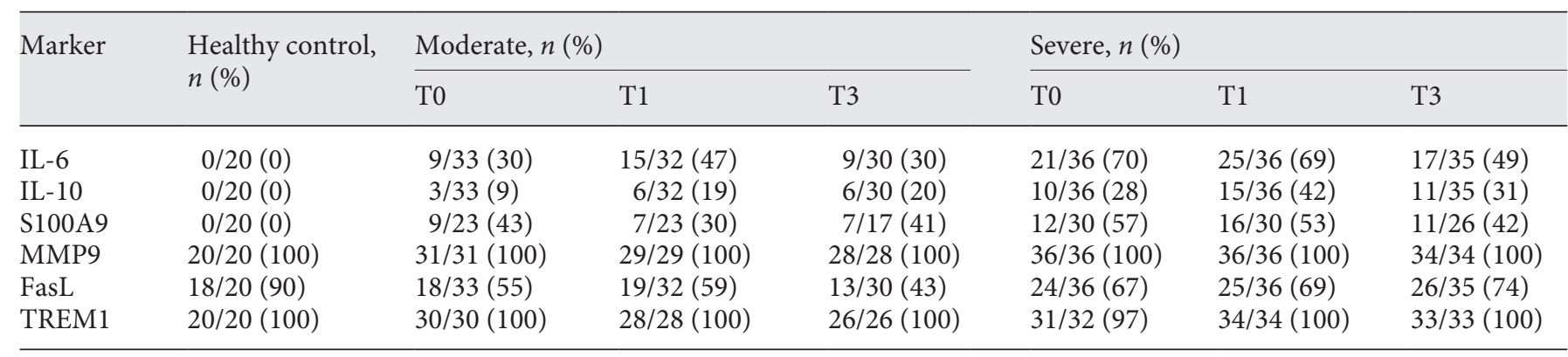

were no differences in expression found between the 3 groups for IL6, S100A8, S100A9, MMP9, FASL, TLR4, MYD88, TREM1 or CD64 (Fig. 1, Table 2).

The number of samples with measureable concentrations for each protein has been summarized in Table 3 , and $p$ values for comparisons are presented in Table 4, both according to group and time point. At T0, only MMP9 was detectable in all samples. The proportion of samples with detectable IL- 6 and S100A9 concentrations were different across the 3 groups $(p \leq 0.001)$. The proportion of samples with detectable IL- 6 concentrations increased significantly with anaphylaxis and again with reaction severity $(p \leq$ $0.015)$. S100A9 was detectable in more samples from anaphylaxis patients than healthy controls $(p \leq 0.002)$, with no difference between reaction severities $(p=1.000)$. After adjustment for multiple comparisons, there were no differences found in the proportion of detectable samples be- tween groups for IL10, soluble FasL, and soluble TREM1 (Table 4 ). For the proteins detected in $>50 \%$ of samples (MMP9, soluble TREM1, and soluble FasL), there were no differences in protein concentrations found between healthy controls, moderate, and severe anaphylaxis at T0 ( $p=0.078, p=0.082, p=0.099$ respectively; Fig. 2 ).

An examination into differences due to reaction trigger (food vs. non-food) identified a significant difference in only 1 protein (soluble TREM1 was lower in food anaphylaxis at T0 and T1, online suppl. Material, see www. karger.com/doi/10.1159/000492301).

\section{Differences Evident after $1 \mathrm{~h}(\mathrm{~T} 1)$}

At T1, expression of IL10, S100A8, S100A9, and MMP9 were different across the 3 groups (healthy controls, moderate, and severe anaphylaxis; $p \leq 0.001$; Fig. 1 ). Of those target genes, only S100A8 and S100A9 had differential ex- 
Table 4. values for comparisons of proportion of samples with detectable protein concentration

\begin{tabular}{|c|c|c|c|c|c|c|c|c|c|c|c|c|}
\hline & \multicolumn{4}{|l|}{ T0 } & \multicolumn{4}{|l|}{$\mathrm{T} 1$} & \multicolumn{4}{|l|}{$\mathrm{T} 3$} \\
\hline IL-6 & $<0.001$ & 0.010 & $<0.001$ & 0.015 & $<0.001$ & $<0.001$ & $<0.001$ & 0.084 & $<0.001$ & 0.007 & $<0.001$ & 0.204 \\
\hline IL-10 & 0.008 & 0.282 & 0.010 & 0.066 & 0.001 & 0.071 & $<0.001$ & 0.065 & 0.011 & 0.069 & 0.004 & 0.398 \\
\hline S100A9 & 0.001 & 0.002 & 0.001 & 1.000 & $<0.001$ & 0.010 & $<0.001$ & 0.162 & 0.001 & 0.002 & 0.001 & 1.000 \\
\hline TREM1 & 1.000 & & & & $\mathrm{~N} / \mathrm{A}$ & & & & $\mathrm{N} / \mathrm{A}$ & & & \\
\hline
\end{tabular}

Bolded $p$ values remained significant after application of Bonferroni-Holm step-down correction to adjust for multiple comparisons. Pairwise comparisons were performed when the Fisher's exact $p$ value for testing across all 3 groups was $<0.05$. HC, healthy control; MOD, moderete; NA, not applicable (all samples detectable); SEV, severe.

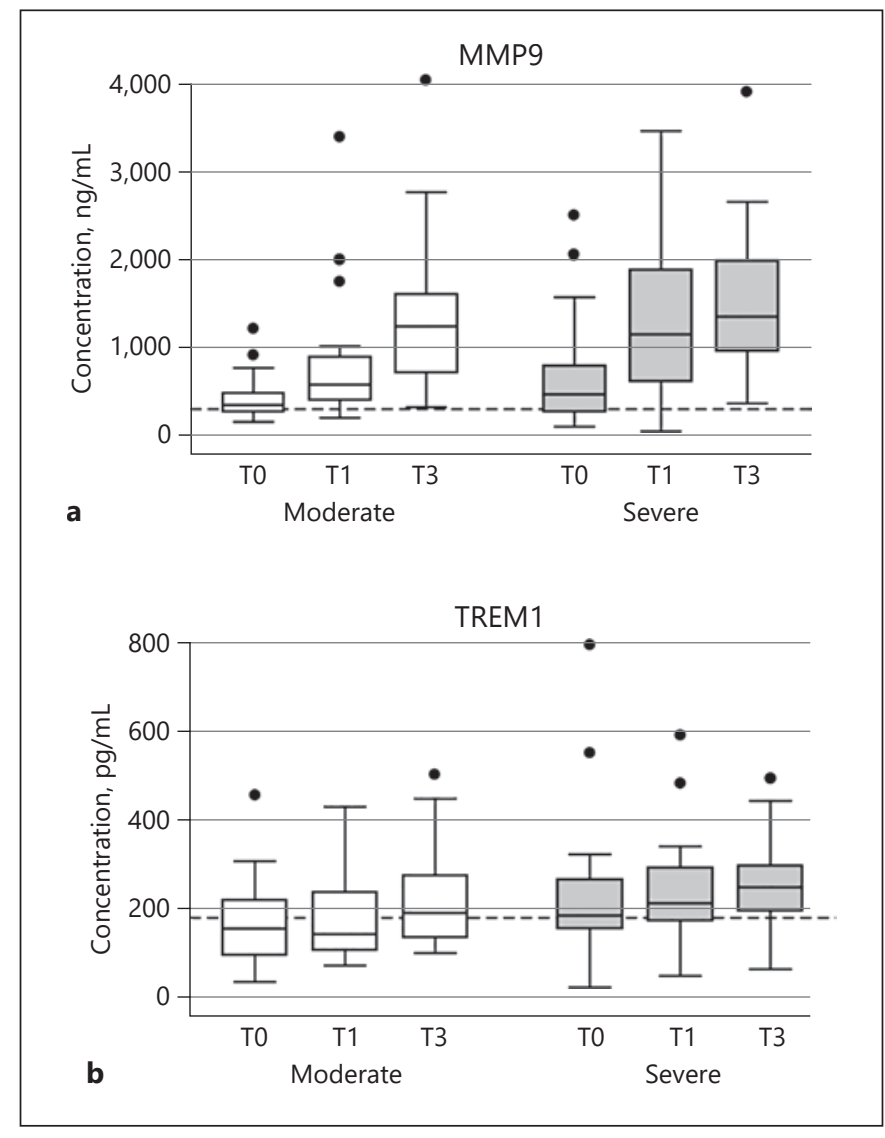

Fig. 2. Protein concentrations during anaphylaxis. a MMP9 and (b) soluble TREM1 in serum from moderate $(n=33)$ and severe $(n=$ 36) anaphylaxis patients at the time of admission to the emergency department (ED; T0), and again after one (T1) and 3 (T3) hours. Boxplots identify the median, upper and lower quartiles, and the range. Dotted lines indicate the median concentration of healthy controls $(n=20): 304.1 \mathrm{ng} / \mathrm{mL}$ MMP9; and $182.3 \mathrm{pg} / \mathrm{mL}$ TREM1. Due to the number and complexity of comparisons, significant differences between groups are described in the results text. pression evident in moderate anaphylaxis compared with healthy controls, and both were elevated $(p=0.045$ and $p=0.006$, respectively). However, all four were elevated in severe anaphylaxis compared with both healthy controls $(p<0.001)$ and moderate anaphylaxis $(p \leq 0.034)$. After adjustment for multiple comparisons, there were no differences found between the 3 groups at T1 in expression of IL6, OSM, FASL, TLR4, MYD88, TREM1, and CD64 ( $p \geq 0.004)$.

Differences in the proportion of detectable samples between healthy controls, moderate, and severe anaphylaxis at T1 were found for IL-6, IL10, and S100A9 ( $p \leq$ 0.001 ; Table 3, 4). At T1, IL-6 and S100A9 were detectable in a higher proportion of anaphylaxis patients than healthy controls $(p \leq 0.010)$, regardless of severity. IL-10 was detectable in a larger proportion of severe patients than healthy controls $(p<0.001)$. After adjustment for multiple comparisons, there were no differences found between groups for soluble FasL at T1 $(p=0.048)$. MMP9 concentrations were 1.8 -fold (95\% CI 1.3-2.5) higher in moderate anaphylaxis than healthy controls ( $p<0.001$; Fig. 2a). Severe anaphylaxis patients had 3.1fold (95\% CI 2.2-4.4) higher MMP9 concentrations than healthy controls $(p<0.001)$, and 1.7 -fold (95\% CI $1.2-2.5)$ higher than moderate anaphylaxis $(p=0.003$; Fig. 2a). We found no difference in soluble TREM1 concentrations between both moderate and severe anaphylaxis patients and healthy controls at $\mathrm{T} 1(p \geq 0.123$; Fig. 2b). However, soluble TREM1 concentrations were 1.3 -fold (95\% CI 1.05-1.7) higher in severe anaphylaxis than moderate anaphylaxis ( $p=0.018$; Fig. $2 b$ ). No differences in soluble FasL concentrations were found between healthy controls, moderate, and severe anaphylaxis $(p \geq 0.260)$. 
Differences Evident after 3 h (T3)

By T3, all target genes except IL6 and MYD 88 were differentially expressed between the 3 groups, after adjustment for multiple comparisons (Fig. 1, Table 2). Expression was higher in moderate anaphylaxis than healthy controls for OSM, S100A8, S100A9, MMP9, TLR4, TREM1, and CD64 ( $p \leq 0.018)$. These 7 targets and IL10 $(p \leq 0.001)$ also had elevated expression in severe anaphylaxis patients compared to that in healthy controls. CD64 had elevated expression in severe compared to moderate anaphylaxis patients $(p=0.010)$. In contrast, FASL expression was reduced in both moderate and severe anaphylaxis patients compared to healthy controls ( $p \leq 0.001$ for both comparisons), with no difference between reaction severities $(p=0.235)$.

At T3, we found differences in the proportion of detectable samples between the 3 groups for IL-6, S100A9, and soluble FasL ( $p \leq 0.001$; Table 3,4$)$. Both IL- 6 and S100A9 were detectable in a higher proportion of moderate and severe anaphylaxis patients than healthy controls $(p \leq 0.007)$. Soluble FasL was detectable in a smaller proportion of moderate patients than either healthy controls or severe patients $(p \leq 0.021)$. MMP9 concentrations were 3.5 -fold (95\% CI 2.6-4.7) higher in moderate anaphylaxis and 4.0-fold (95\% CI 2.9-5.4) higher in severe anaphylaxis than controls ( $p<0.001$ for both tests), but not different from each other ( $p=0.377$; Fig. 2a). At T3, soluble TREM1 concentrations in severe anaphylaxis patients were 1.4-fold (95\% CI 1.1-1.7) higher than those in controls $(p=0.005)$. There was no difference between moderate anaphylaxis and controls, or between reaction severity groups ( $p=0.205$ and $p=0.168$, respectively; Fig. $2 b$ ). We found no difference in soluble FasL concentrations between healthy controls and severe anaphylaxis at T3 $(p=0.854)$. We were unable to investigate other differences in concentrations as $<50 \%$ of samples were detectable.

\section{Discussion}

As a validation of results of a previous microarray investigation by our group [7], this study provides evidence of association with anaphylaxis in nearly all of the selected mRNA and/or protein targets. Taken together, the results provide support for the hypothesis that innate immune pathways and myeloid cells such as neutrophils are activated during human anaphylaxis. The clinical relevance of this innate immune activation remains unclear and future studies are required.
The cytokine results validate the microarray analysis and support previously reported findings in a different cohort of anaphylaxis patients $[7,19]$. The increases observed in these cytokines during anaphylaxis highlight the involvement of innate immune cell activation. IL-6 and its family member OSM are proinflammatory cytokines, while IL-10 is an anti-inflammatory cytokine. Elevated IL- 6 concentrations are evident in allergic asthma patients [20], a condition that shares many similarities with anaphylaxis. OSM concentrations were also elevated in asthmatics, following allergen but not saline challenge [21]. They are released from a number of cell types including mast cells, macrophages, and neutrophils $[8,9]$. Due to the proinflammatory functions of IL-6 and OSM, their release during a reaction likely contributes to the symptoms of anaphylaxis. In contrast, IL-10 has been found to reduce anaphylaxis following the challenge of sensitized mice [22-24]. The upregulation and release of IL-10 evident in our cohort likely represents a counterregulatory response to restore homeostasis. The severity of a reaction could be, in part, determined by the relative concentrations of the pro- and anti-inflammatory cytokines released, with IL-6/OSM dominance resulting in poorer outcomes and IL-10 dominance improving symptom resolution.

During anaphylaxis, both S100A8 and S100A9 were upregulated and with increasing extent as the reactions progressed and resolved, validating the microarray data [7]. There was a marked increase in S100A9 protein in patients, and by association, the same is likely true for S100A8 [25]. Activated neutrophils export large amounts of S100A8 and S100A9, both separately and as the heterodimer calprotectin. Although other phagocytes contain and export these molecules, neutrophils are considered to be their primary producers [25]. Therefore, the results of this study are strongly suggestive of neutrophil activation, supporting previous findings from our laboratory [18]. Once exported, these proteins function as danger-associated molecular patterns that amplify inflammatory responses via binding to TREM1 and TLR4 receptors on innate immune cells [26, 27]. Ligand binding to TREM1 triggers the cell to express additional activation receptors, thereby amplifying inflammatory responses $[28,29]$. TLR4 is a pattern recognition receptor that signals cell activation in conjunction with its adaptor protein MyD88 [30, 31]. Our observations of elevated TREM 1 and TLR4, coupled with upregulation of S100A8 and $S 100 A$, suggest this signaling pathway as a mechanism for amplifying innate immune signals during anaphylaxis. 
Membrane-bound TREM1 receptors are cleaved by matrix metalloproteinases (MMPs) [32], and both soluble TREM1 and MMP9 concentrations were increased during anaphylaxis. Soluble TREM1 can reduce inflammation by binding to TREM1 ligands in the serum, thereby preventing them from binding to membranebound TREM1 [32]. MMP9 is an enzyme produced by leukocytes that degrades the extracellular matrix and basement membrane [33]. Increases in MMP9 have been reported following exacerbation of allergic asthma and in patients with allergic bronchopulmonary aspergillosis (a hypersensitivity reaction to fungus) [34, 35]. In addition, elevated serum MMP9 has been observed following allergen challenge in a mouse model [36]. Elevated MMP9 in anaphylaxis may cause extracellular matrix degradation, allowing inflammatory cells to diffuse into tissues and provoke signs such as erythema and angioedema. However, this increase in MMP9 during anaphylaxis may cause TREM1 shedding, with soluble TREM1 acting as an indirect mechanism for dampening systemic inflammation.

FasL is a membrane-bound ligand for Fas that plays an important role in regulating apoptosis and, in some cases, necrosis $[13,37]$. Following shedding from the cell surface by MMPs, soluble FasL can still bind to Fas; however, this no longer results in apoptosis [14]. Therefore, soluble FasL acts as a competitive inhibitor of membrane-bound FasL, and so minimizes apoptosis. The reduction in FASL expression over the course of anaphylaxis may reflect an increased translation of transcripts into surface FasL, as immune cells are activated and subsequently prepared for apoptosis. In addition, the reduction in soluble FasL supports a pro-apoptotic environment, which would be necessary to clear inflammatory cells following anaphylaxis.

CD64, also known as Fc $\gamma \mathrm{RI}$, is a high-affinity IgG receptor present on the surface of human neutrophils, monocytes, and macrophages [38]. In mouse models, binding of IgG to CD64 induces systemic (IgG-mediated) anaphylaxis, in addition to other inflammatory disorders such as autoimmune arthritis and airway inflammation [38]. The upregulation of CD64 mRNA reported here is expected to correlate with increased surface expression [39], which would need to be confirmed using flow cytometry or microscopy. Additional CD64 expression on leukocytes increases the likelihood of future reactions occurring via the proposed IgG-mediated anaphylaxis pathway.

The clinical relevance of the innate immune activation observed in this study is currently unclear. Such innate responses could be a bystander response due to the abun-

Innate Immunity and Neutrophils in Anaphylaxis dance of neutrophils (approximately $60 \%$ of peripheral blood leukocytes), and their potential to be mobilized by treatment with adrenaline [40]. Alternatively, these innate immune cells may play a specific role in amplifying initial immune signals, thereby contributing to the systemic physiological symptoms of anaphylaxis. We have observed no evidence to suggest that the innate immune activation prolongs the symptoms of anaphylaxis, or encourages a biphasic reaction. Conversely, their activation may serve to control the reaction and attempt to restore homeostasis through the removal of excess cytokines, mediators, and inappropriately activated cells from the peripheral circulation via phagocytosis.

In conclusion, the findings of this study have provided support for the involvement of the innate immune system during anaphylaxis, particularly the activation of granulocytes such as neutrophils. Products released from neutrophils, such as MMP9 and other potent antimicrobials, can cause non-specific tissue damage. Therefore, the widespread activation of neutrophils may not only amplify the inflammatory signal systemically, but also contribute to the clinical features of anaphylaxis. Further analysis into the surface protein expression of these receptors by flow cytometry or microscopy would improve our understanding of the mechanisms driving receptor production, expression, and cleavage. Additionally, studies investigating the roles of the innate immune cells, such as neutrophils, during anaphylaxis may open up new avenues for improved treatments, prevention, and screening for at-risk individuals.

\section{Limitations}

There are limitations to this study that should be acknowledged. First, the assays were performed using whole blood and serum, thus the cellular source(s) of the gene expression signals and protein mediators is unclear. There was a limit to the number of targets we could analyze due to the amount of sample collected from patients. Also, as these patients were recruited under an observational study, no restrictions were made on the treatment delivered. While at enrolment most patients are untreated, it is impossible to be certain whether the changes observed at later time points are influenced by the treatment administered. Future mechanistic studies will assist in further exploring the role/s of these targets. Lastly, while comparisons to healthy controls may not be ideal in the setting of anaphylaxis, the design of the CISS protocol only sampled patients until discharge, and therefore we were unable to analyses changes in these targets relative to each patient's individual baseline. 


\section{Acknowledgements}

The authors appreciate and acknowledge the clinical investigators and research nursing staff at Royal Perth, Fremantle, Armadale, and Austin hospitals, including Ellen MacDonald (Clinical Nurse Manager), for identifying patients for the study and collecting and processing blood samples. The authors also appreciate Mrs Claire Neil for her expert assistance in optimizing the laboratory methods. The authors acknowledge the facilities, scientific and technical assistance of the Australian Microscopy and Microanalysis Research Facility at the Centre for Microscopy, Characterisation and Analysis, University of Western Australia, a facility funded by the University, State and Commonwealth Governments. Prof. Simon Brown was supported by an NHMRC Career Development Fellowship ID1023265, and laboratory work was supported by the RPH Medical Research Foundation. Funding bodies played no role in study design, data collection, or analysis.

\section{Disclosure Statement}

The authors declare that they have no conflicts of interest to disclose.

\section{Author Contributions}

All authors reviewed and approved the final manuscript. A.F. contributed to the study concept and design, performed the laboratory experiments, contributed to data analysis, and drafted the manuscript. E.B. contributed to the data analysis and manuscript preparation. S.F.S. contributed to the study concept and design, and assisted in obtaining funding support. D.M.F., G.A., and S.P.J.M. contributed to the collection of data. S.B. contributed extensive statistical knowledge to assist in data analysis and interpretation. S.G.A.B. contributed to the study concept and design, obtaining funding support, and collection of data.

\section{References}

1 Poulos LM, Waters AM, Correll PK, Loblay RH, Marks GB: Trends in hospitalizations for anaphylaxis, angioedema, and urticaria in Australia, 1993-1994 to 2004-2005. J Allergy Clin Immunol 2007;120:878-884.

-2 Sampson HA, Muñoz-Furlong A, Campbell RL, Adkinson Jr NF, Bock SA, Branum A, Brown SGA, Camargo Jr CA, Cydulka R, Galli SJ, Gidudu J, Gruchalla RS, Harlor Jr AD, Hepner DL, Lewis LM, Lieberman PL, Metcalfe DD, O'Connor R, Muraro A, Rudman A, Schmitt C, Scherrer D, Simons FER, Thomas S, Wood JP, Decker WW: Second symposium on the definition and management of anaphylaxis: summary report-second national institute of allergy and infectious disease/food allergy and anaphylaxis network symposium. J Allergy Clin Immunol 2006;117:391-397.

-3 Simons FER: Anaphylaxis. J Allergy Clin Immunol 2010;125(2 suppl 2):S161-S181.

4 Metcalfe DD, Peavy RD, Gilfillan AM: Mechanisms of mast cell signaling in anaphylaxis. J Allergy Clin Immunol 2009;124:639-646.

-5 Stone SF, Cotterell C, Isbister GK, Holdgate A, Brown SG: Elevated serum cytokines during human anaphylaxis: Identification of potential mediators of acute allergic reactions. J Allergy Clin Immunol 2009;124:786-792.

-6 Ogawa Y, Grant JA: Mediators of anaphylaxis. Immunol Allergy Clin North Am 2007;27: 249-260.

7 Stone SF, Bosco A, Jones A, Cotterell CL, van Eeden PE, Arendts G, Fatovich DM, Brown SG: Genomic responses during acute human anaphylaxis are characterized by upregulation of innate inflammatory gene networks. PLoS One 2014;9:e101409.

8 Doganci A, Sauer K, Karwot R, Finotto S: Pathological role of IL-6 in the experimental allergic bronchial asthma in mice. Clin Rev Allergy Immunol 2005;28:257-269.
9 Grenier A, Dehoux M, Boutten A, Arce-Vicioso M, Durand G, Gougerot-Pocidalo M-A, Chollet-Martin S: Oncostatin M production and regulation by human polymorphonuclear neutrophils. Blood 1999;93: 1413-1421.

10 Foell D, Wittkowski H, Vogl T, Roth J: S100 proteins expressed in phagocytes: a novel group of damage-associated molecular pattern molecules. J Leukoc Biol 2007;81:2837.

11 Donato R, Cannon BR, Sorci G, Riuzzi F, Hsu K, Weber DJ, Geczy CL: Functions of S100 proteins. Curr Mol Med 2013;13:24-57.

12 Chakrabarti S, Zee JM, Patel KD: Regulation of matrix metalloproteinase-9 (MMP-9) in TNF-stimulated neutrophils: novel pathways for tertiary granule release. J Leukoc Biol 2006;79:214-222.

13 Wajant H: The Fas signaling pathway: more than a paradigm. Science 2002;296:16351636.

14 Hohlbaum AM, Moe S, Marshak-Rothstein A: Opposing effects of transmembrane and soluble Fas ligand expression on inflammation and tumor cell survival. J Exp Med 2000; 191:1209-1220.

15 Khodoun MV, Strait R, Armstrong L, Yanase N, Finkelman FD: Identification of markers that distinguish IgE-from IgG-mediated anaphylaxis. Proc Natl Acad Sci U S A 2011;108: 12413-12418.

16 Arendts G, Stone SF, Fatovich DM, van Eeden P, MacDonald E, Brown SG: Critical illness in the emergency department: lessons learnt from the first 12 months of enrolments in the critical Illness and Shock Study. Emerg Med Australas 2012;24:31-36.

17 Brown SG: Clinical features and severity grading of anaphylaxis. J Allergy Clin Immunol 2004;114:371-376.
18 Francis A, Bosio E, Stone SF, Fatovich DM, Arendts G, Nagree Y, Macdonald SP, Mitenko H, Rajee M, Burrows S: Neutrophil activation during acute human anaphylaxis: analysis of MPO and sCD62L. Clin Exp Allergy 2017;47:361-370.

19 Martino DJ, Prescott SL: Silent mysteries: Epigenetic paradigms could hold the key to conquering the epidemic of allergy and immune disease. Allergy 2010;65:7-15.

20 Neveu WA, Allard JL, Raymond DM, Bourassa LM, Burns SM, Bunn JY, Irvin CG, Kaminsky DA, Rincon M: Elevation of IL-6 in the allergic asthmatic airway is independent of inflammation but associates with loss of central airway function. Respiratory Res 2010;11: 28.

21 Pothoven KL, Norton JE, Hulse KE, Suh LA, Carter RG, Rocci E, Harris KE, ShintaniSmith S, Conley DB, Chandra RK: Oncostatin M promotes mucosal epithelial barrier dysfunction, and its expression is increased in patients with eosinophilic mucosal disease. J Allergy Clin Immunol 2015;136: 737-746.

22 Frossard CP, Steidler L, Eigenmann PA: Oral administration of an IL-10-secreting Lactococcus lactis strain prevents food-induced IgE sensitization. J Allergy Clin Immunol 2007; 119:952-959.

23 Kennedy Norton S, Barnstein B, Brenzovich J, Bailey DP, Kashyap M, Speiran K, Ford J, Conrad D, Watowich S, Moralle MR, Kepley CL, Murray PJ, Ryan JJ: IL-10 Suppresses mast cell IgE receptor expression and signaling in vitro and in vivo. J Immunol 2008;180: 2848-2854.

24 Royer B, Varadaradjalou S, Saas P, Guillosson J, Kantelip J, Arock M: Inhibition of IgE-induced activation of human mast cells by IL10. Clin Exp Allergy 2001;31:694-704. 
25 Ryckman C, Vandal K, Rouleau P, Talbot M, Tessier PA: Proinflammatory activities of S100: proteins S100A8, S100A9, and S100A8/ A9 induce neutrophil chemotaxis and adhesion. J Immunol 2003;170:3233-3242.

26 Ehrchen JM, Sunderkotter C, Foell D, Vogl T, Roth J: The endogenous Toll-like receptor 4 agonist S100A8/S100A9 (calprotectin) as innate amplifier of infection, autoimmunity, and cancer. J Leukoc Biol 2009;86:557-566.

-27 Arts RJ, Joosten LA, Dinarello CA, Kullberg BJ, van der Meer JW, Netea MG: TREM-1 interaction with the LPS/TLR4 receptor complex. Eur Cytokine Netw 2011;22:11-14.

28 Dower K, Ellis DK, Saraf K, Jelinsky SA, Lin L-L: Innate immune responses to TREM- 1 activation: overlap, divergence, and positive and negative cross-talk with bacterial lipopolysaccharide. J Immunol 2008; 180:3520-3534.

-29 Bouchon A, Facchetti F, Weigand MA, Colonna M: TREM-1 amplifies inflammation and is a crucial mediator of septic shock. Nature 2001;410:1103-1107.

-30 Berin MC, Zheng Y, Domaradzki M, Li XM, Sampson HA: Role of TLR4 in allergic sensitization to food proteins in mice. Allergy 2006;61:64-71.
Piggott DA, Eisenbarth SC, Xu L, Constant SL, Huleatt JW, Herrick CA, Bottomly K MyD88-dependent induction of allergic Th2 responses to intranasal antigen. J Clin Invest 2005;115:459-467.

32 Bucova M, Suchankova M, Dzurilla M, Vrlik M, Novosadova H, Tedlova E, Urban S, Hornakova E, Seligova M, Durmanova V: Inflammatory marker sTREM-1 reflects the clinical stage and respiratory tract obstruction in allergic asthma bronchiale patients and correlates with number of neutrophils. Mediators Inflamm 2012;2012:628754.

33 Delclaux C, Delacourt C, d'Ortho M-P, Boyer V, Lafuma C, Harf A: Role of gelatinase B and elastase in human polymorphonuclear neutrophil migration across basement membrane. Am J Respir Cell Mol Biol 1996;14: 288-295.

34 Becky Kelly EA, Busse WW, Jarjour NN: Increased matrix metalloproteinase-9 in the airway after allergen challenge. Am J Respir Crit Care Med 2000;162:1157-1161.

35 Gibson PG, Wark PAB, Simpson JL, Meldrum C, Meldrum S, Saltos N, Boyle M: Induced sputum IL-8 gene expression, neutrophil influx and MMP-9 in allergic bronchopulmonary aspergillosis. Eur Respir J 2003;21: 582-588.
36 Cataldo DD, Tournoy KG, Vermaelen K, Munaut C, Foidart J-M, Louis R, Noël A, Pauwels RA: Matrix metalloproteinase- 9 deficiency impairs cellular infiltration and bronchial hyperresponsiveness during allergen-induced airway inflammation. Am J Pathol 2002;161: 491-498.

37 Nagata S, Golstein P: The Fas death factor. Science 1995;267:1449.

38 Mancardi DA, Albanesi M, Jönsson F, Iannascoli B, Van Rooijen N, Kang X, England P, Daëron M, Bruhns P: The high-affinity human IgG receptor Fc $\gamma$ RI (CD64) promotes IgG-mediated inflammation, anaphylaxis, and antitumor immunotherapy. Blood 2013; 121:1563-1573.

39 Kern W, Kohlmann A, Wuchter C, Schnittger S, Schoch C, Mergenthaler S, Ratei R, Ludwig W-D, Hiddemann W, Haferlach T: Correlation of protein expression and gene expression in acute leukemia. Cytometry B Clin Cytom 2003;55B:29-36.

40 Burns AM, Keogan M, Donaldson M, Brown DL, Park GR: Effects of inotropes on human leucocyte numbers, neutrophil function and lymphocyte subtypes. Br J Anaesth 1997;78: 530-535. 